\title{
EL CONSTITUCIONALISMO IMPOSIBLE DE LUIGI FERRAJOLI*
}

\author{
Josep Aguiló Regla \\ Universidad de Alicante
}

RESUMEN. El trabajo es una crítica a la concepción del constitucionalismo jurídico defendida por FERRAJOLI. Se concluye que el constitucionalismo que propone es impracticable porque su asunción desemboca en sinsentidos prácticos. Para mostrarlo, el trabajo se centra en la crítica de tres tesis ferrajolianas: 1) la tesis de la rigidez (el Estado constitucional se identifica jurídicamente sólo por la lex superior); 2) la tesis de la normatividad (no hay diferencia estructural entre principios y reglas), y 3) la tesis de la correlatividad (los enunciados de derechos significan exactamente lo mismo que los enunciados que expresan sus deberes correlativos). Cada una de estas tesis se cruza con tres momentos (y/o contextos) que, en opinión del autor, una buena teoría de la constitución debe ser capaz de distinguir y de integrar: 1) «Tener una constitución»; 2) «darse una constitución», y 3) «vivir en constitución».

Palabras-clave: FerRAJol, constitucionalismo, positivismo jurídico, post-positivismo.

ABSTRACT. The paper is a critique of the conception of legal constitutionalism defended by FERRAJOLI. The conclusion is that the constitutionalism that he proposes is not practicable because his assumption ends in practical nonsenses. To show it, the paper focuses on the critique of three main theses: 1) the rigidity thesis (the Constitutional State is legally identified just by lex superior); 2) the normativity thesis (there is no structural difference between principles and rules), and 3) the correlativity thesis (sentences of rights mean exactly the same that sentences that express their correlative duties). Each one of these theses is crossed with three different moments (and/or contexts) that according to the author a good theory of the constitution must be able to distinguish and to integrate: 1) The moment of having a constitution; 2) the moment of giving ourselves a constitution, and 3 ) the moment of living according to a constitution (of practicing it).

Keywords: FERRAJOLI, constitutionalism, legal positivism, post-positivism.

* Fecha de recepción: 10 de enero de 2011. Fecha de aceptación: 7 de febrero de 2011.

Este escrito se enmarca en el proyecto «Argumentación y constitucionalismo» (Ref. DER2010-21032) del Plan Nacional I+D+I (2008-2011) del Ministerio de Ciencia y Tecnología. 


\section{INTRODUCCIÓN}

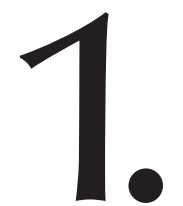

Dos temas han acaparado la discusión en teoría del Derecho en las últimas décadas. El primero de estos temas ha sido el de la vigencia y/o la superación del positivismo jurídico. Uno de los resultados producidos por esta discusión ha sido el desplazamiento de la tradicional contraposición entre iusnaturalismo y iuspositivismo por la más vigente que opone los autores (teorías) positivistas a los autores (teorías) post-positivistas. La razón de este cambio radica en que prácticamente todo el mundo acepta la tesis positivista de las fuentes sociales del Derecho (nadie — o casi nadie- sostiene que haya Derecho o principios jurídicos fuera de la historia). La discrepancia entre unos autores y otros se fija, pues, en torno al otro gran principio del positivismo jurídico: el de la separación conceptual entre Derecho y moral. El segundo tema de discusión ha sido el del (mal) llamado (neo-constitucionalismo o) constitucionalismo jurídico. La discusión ha versado sobre el tránsito del Estado legal de Derecho al Estado constitucional de Derecho; y ha girado en torno a, por un lado, cuestiones de justificación y, por otro, cuestiones metodológicas (si dicha transición implica o no un cambio de paradigma jurídico).

Estas dos cuestiones presentan un nivel de solapamiento en los contenidos que ha tendido a crecer. Por decirlo en la terminología de Ross, se trata de una superposición de tipo «parcial-parcial» que muestra, en algunos países, una tendencia expansiva hacia la superposición «total-total». Piénsese, por ejemplo, en la siguiente enumeración de temas comunes: principios y reglas; observador, participante y aceptante; el Derecho como sistema y el Derecho como práctica; subsunción y ponderación; discrecionalidad y única respuesta correcta; la correlatividad entre derechos y deberes; casos regulados/ no regulados y casos fáciles/difíciles; lagunas normativas y lagunas axiológicas; aplicación del Derecho y derrotabilidad de las normas; interpretación intencionalista y/o literal e interpretación orientada por valores; lealtad a las normas y lealtad a las razones subyacentes a las normas; etc. Esta enumeración de temas comunes podría ampliarse, pero es más que suficiente para ilustrar la amplia intersección entre la cuestión del positivismo jurídico y la cuestión del constitucionalismo jurídico.

En términos generales, puede decirse que los autores que consideran plenamente vigente el positivismo jurídico tienden a ser escépticos, o a mostrar muchas prevenciones, a propósito de la evolución del Estado legal de Derecho hacia el Estado constitucional. Además tienden también a pensar que no hay en realidad un nuevo paradigma jurídico, sino un simple desplazamiento de poder en favor de los jueces y, en consecuencia, un puro incremento de la discrecionalidad (en el sentido de libertad de elección) judicial. Otros autores, por el contrario, tienden a valorar positivamente la referida evolución hacia el Estado constitucional de Derecho y, por tanto, o bien consideran que ya no tiene sentido seguir sosteniendo la tesis positivista de la separación entre el Derecho y la moral; o bien piensan que se ha hecho patente el error de una tesis (la de la separación) que siempre estuvo equivocada. Tanto en un caso como en otro, estos últimos autores tienden a considerar que el desarrollo del constitucionalismo jurídico está suponiendo el fin del ciclo histórico y/o teórico del positivismo jurídico. En este sentido y en términos generales, se ven a sí mismos como post-positivistas. 
2. Luigi FERRAJOLI es, sin duda, uno de los autores en lenguas latinas que más ha contribuido a la extensión de la conciencia de la relevancia de los cambios que en el mundo jurídico ha producido el constitucionalismo que se ha desarrollado desde la Segunda Guerra Mundial hasta nuestros días. Él ha insistido particularmente en la idea de «cambio de paradigma». Junto a ello, además, ha procedido a una defensa cerrada del positivismo jurídico. Así, frente a quienes han pensado que el constitucionalismo jurídico habría supuesto una superación del positivismo, él ha enfatizado mucho la idea de que representa su expansión o culminación, pues — como suele decir- se ha hecho positivo no sólo el «ser» del Derecho (la legislación), sino también su «deber ser» (la constitución sustantiva). En este sentido, no cabe duda de que se trata de un autor que no encaja en las tendencias anunciadas en el parágrafo anterior. Lejos de dejarse arrastrar por las «corrientes» se muestra como un firme (y simultáneo) defensor tanto del iuspositivismo como del constitucionalismo jurídico.

3. En este trabajo me propongo criticar la concepción del constitucionalismo de Luigi FERRAJOLI centrándome principalmente en su trabajo «Constitucionalismo principialista y constitucionalismo garantista» ${ }^{1}$. La tesis que voy a sostener es que el constitucionalismo que FERRAJOLI propone es impracticable porque su asunción desemboca en sinsentidos prácticos. Para tratar de mostrarlo voy a detenerme en tres tesis de FERRAJOLI que llamaré respectivamente: 1) la tesis de la rigidez (el Estado constitucional se identifica jurídicamente sólo por la lex superior); 2) la tesis de la normatividad (no hay diferencia estructural entre principios y reglas y la insistencia en la misma produce un debilitamiento de la obligatoriedad de la constitución), y 3 ) la tesis de la correlatividad (los enunciados de derechos significan exactamente lo mismo que los enunciados que expresan sus deberes correlativos). Estas tres tesis no abarcan todo lo sostenido por FERRAJOLI en el trabajo aquí criticado pero sí son plenamente representativas de su constitucionalismo positivista.

Para estructurar mi crítica voy a cruzar cada una de estas tesis de FERRAJOLI con tres momentos (y/o contextos) que, en mi opinión, una buena teoría de la constitución debe ser capaz de distinguir y de integrar. Me refiero a los siguientes: 1) «Tener una constitución» (en el que se incluyen los problemas estructurales y de identificación del Estado constitucional y/o de la constitución del Estado constitucional; es decir, lo que podríamos llamar la estática constitucional). 2) «Darse una constitución» (en el que se incluyen las peculiaridades de la constitución como fuente-acto; lo que implica hablar de promulgación de la constitución y de poder constituyente). Y 3) «vivir en constitución» (en el que se incluyen las peculiaridades de la dinámica constitucional que no se dejan reducir a la noción de sistema y que remiten a la idea de práctica constitucional) ${ }^{2}$. El cruce de las tres tesis de FERRAJOLI con los tres momentos referidos genera

${ }^{1}$ L. FERRAJOLI, «Constitucionalismo principialista y constitucionalismo garantista», N. GUZMÁN (trad.), en Doxa. Cuadernos de Filosofía del Derecho, núm. 34, 2010, 15 y ss.

2 Prefiero no detenerme ahora a explicar con precisión la distinción de estos tres momentos (y/o contextos) y entrar directamente en lo importante: la crítica del constitucionalismo de FERRAJOLI. Ello no será obstáculo, me parece, para que al final el lector se haga una idea clara del porqué y del alcance de la distinción. En cualquier caso, la he desarrollado en J. AgUILÓ REGLA, «"Tener una Constitución", "darse una Constitución” y "vivir en Constitución”", en Isonomía. Revista de Teoría y Filosofía del Derecho, núm. 28, abril 2008, 6786. Una versión muy semejante puede verse en «Sobre las contradicciones (tensiones) del constitucionalismo y las concepciones de la Constitución», en M. CARBONELl y L. GARCíA JARAmillo (eds.), El canon neoconstitucional, Bogotá, Universidad Externado, 2010, 229-246. 
nueve ítems de discusión. Hay que advertir, sin embargo, que las fronteras entre ellos serán ciertamente fluidas.

Alguien podría pensar que esta forma de proceder es desleal con FERRAJOLI porque supone modificar de manera drástica el terreno de juego que él previamente ha fijado. Sin embargo, esa modificación es completamente necesaria para no incurrir en esa especie de «segregacionismo discursivo» que FERRAJOLI practica de manera estric$\operatorname{ta}^{3}$ y que, en mi opinión, constituye una peligrosa fuente de falacias. Porque una cosa es introducir y usar distinciones para poner orden en el discurso sobre el Derecho, y otra muy distinta, fragmentar la experiencia y la fenomenología jurídicas en múltiples discursos desconectados y opuestos entre sí. Si bien se considera, este «segregacionismo discursivo» está en la base de lo que, en mi opinión, es el reproche más general que puede dirigirse a FERRAJOLI: la pretensión de construir un «constitucionalismo jurídico no constitucionalista»; o, dicho en términos algo menos paradójicos, de separar completamente el «constitucionalismo jurídico» del «constitucionalismo político». Así escribe:

«[...] el constitucionalismo "jurídico" o, si se prefiere, el "ius-constitucionalismo", designa un sistema jurídico y/o una teoría del Derecho, ambos ligados a la experiencia histórica del constitucionalismo del siglo XX, tal como se afirmó con las constituciones rígidas de la segunda posguerra. Algo completamente distinto es el constitucionalismo "político" —moderno pero también antiguo- como práctica y como concepción de los poderes públicos dirigidas a su limitación, en garantía de determinados ámbitos de libertad: en este sentido, tanto los límites a los poderes como las garantías de las libertades, son límites y garantías reivindicados y acaso realizados como límites y garantías políticas externas a los sistemas jurídicos, y no, ciertamente, como límites y garantías jurídicas internos a los mismos. Sin embargo, es en oposición a esta noción política de constitucionalismo como se ha venido afirmando, en el léxico y en el debate filosófico-jurídico, la expresión "neoconstitucionalismo", referida a la experiencia jurídica de las actuales democracias constitucionales» (pp. 17 y 18. La negrita es mía).

El énfasis puesto en la separación no está destinado a tomar conciencia de la intensidad de los cambios producidos en el interior del constitucionalismo, sino a separar y encapsular los discursos jurídico y político sobre la constitución. Sin embargo, la división de poderes es un principio jurídico-político fundamental que recorre «todo» el constitucionalismo. La falacia no está en distinguir, sino en segregar ${ }^{4}$.

3 Según ATIENZA, FerRAjOLI para «blindar» su teoría frente a los críticos «utiliza básicamente dos estrategias argumentativas (basadas en lo que PERELMAN llamaba "técnicas de disociación"): el carácter formal de su teoría, y la distinción entre el discurso de la teoría del Derecho y el propio de la dogmática, la sociología, la historia o la filosofía política y moral». M. ATIENZA, «Sobre Ferrajoli y la superación del positivismo jurídico», en L. Ferrajoli, J. J. Moreso y M. AtiEnZA, La teoría del Derecho en el paradigma constitucional, Madrid, Fundación Coloquio Jurídico Europeo, 2008, 157-158.

${ }^{4}$ En mi opinión, el contramodelo de FerRajoli lo representa Carlos S. NinO. El eslogan de FerRajoli podría ser «distinguir para segregar»; el de NiNO, «distinguir para integrar». Así, por ejemplo, a propósito de esta misma cuestión de las relaciones entre el constitucionalismo político y el jurídico, NiNo introduce la noción de «constitucionalismo pleno» y escribe: «Este sentido [el constitucionalismo] requiere no sólo la existencia de normas que organicen el poder y que están en cierto modo atrincheradas frente al proceso legislativo normal, sino también y preeminentemente que se satisfagan ciertas exigencias acerca del procedimiento y contenido de las leyes que regulan la vida pública. Este es el sentido expresado por el art. 16 de la Declaración francesa de los derechos cuando dice que "una sociedad en la que la garantía de los derechos no está asegurada, ni la separación de poderes determinada, no tiene una Constitución". Estas exigencias son las que definen el concepto de democracia liberal o constitucional» (C. S. Nino, Fundamentos de Derecho constitucional. Análisis filosófico, jurídico y politológico de la práctica constitucional, Buenos Aires, Astrea, 1992, 4. 


\section{A PROPÓSITO DE LA TESIS DE LA RIGIDEZ}

La tesis de la rigidez sostiene que el Estado constitucional de Derecho (o la constitución del Estado constitucional) se identifica sólo por la lex superior, es decir, por rasgos puramente estructurales (formales) y avalorativos.

1.1. En Tener una constitución incluyo los componentes estáticos de la teoría de la constitución, es decir, los problemas de identificación del Estado constitucional y/o de la constitución del Estado constitucional.

Escribe y estipula FERRAJOLI:

«Así, será conveniente utilizar la expresión "ius-constitucionalismo" o "constitucionalismo jurídico", o mejor aun "Estado constitucional de Derecho" o simplemente "constitucionalismo", para designar —en oposición al "Estado legal" o "Estado legislativo de Derecho", privado de constitución o dotado de constitución flexible— al constitucionalismo rígido de las actuales democracias constitucionales, cualquiera sea su concepción filosófica y metodológica. En este sentido, el rasgo distintivo del constitucionalismo será la existencia positiva de una lex superior a la legislación ordinaria, con independencia de las diversas técnicas adoptadas para garantizar su superioridad [...]» (p. 14. La negrita es mía).

Como se ve, en el párrafo se alude a las «democracias constitucionales» (que quedan en el trasfondo del discurso) para inmediatamente estipular que el Estado constitucional de Derecho se identifica «sólo» por la existencia positiva de una lex superior a la legislación. Es decir, por un lado, se «alude» a las democracias constitucionales y, por otro, inmediatamente se «elude» la cuestión sustantiva y política. Frente a esta actitud, y parafraseando a Elías DíAz, uno se siente tentado de decir bien alto y claro que del mismo modo que no todo Estado que tiene legislación es un Estado legal de Derecho, no todo Estado que tiene una constitución rígida y normativa (la lex superior de la que habla FERRAJOLI) es un Estado constitucional ${ }^{5}$. Por sí misma la lex superior identifica tan poco al Estado constitucional de Derecho como la lex posterior al Estado legal (o legislativo) de Derecho. El «Estado de Derecho», en general, no es simplemente observable a partir de puros rasgos estructurales. Todos sabemos, por ejemplo, que la rigidez constitucional orientada a preservar la «verdadera religión» (es decir, a negar la libertad religiosa) es incompatible con lo que llamamos Estados constitucionales;

5 Hace ya muchos años, en 1966, Elías Díaz comenzaba su conocidísimo libro Estado de Derecho y sociedad democrática con un lapidario «No todo Estado es un Estado de Derecho». Esta frase pretendía cumplir algunas funciones coyunturales vinculadas a la resistencia democrática española a la dictadura franquista; pero la frase en cuestión tenía (y tiene) un sentido teórico que trasciende con mucho a aquella coyuntura política. El concepto de «Estado de Derecho», viene a decir la frase, no es sólo un concepto descriptivo-clasificatorio, es también —y de manera muy relevante- un concepto valorativo. Ello es muy importante por lo siguiente: el Estado de Derecho no coincide simplemente con la juridicidad o la legalidad como parecen suponer muchos juristas positivistas. Si así fuera, todo Estado moderno sería un Estado de Derecho, pues ningún Estado puede prescindir del Derecho como un instrumento para guiar y controlar las conductas. Es, pues, un concepto normativo/valorativo cuya función no es describir una mera propiedad del Derecho moderno. Es un concepto normativo/valorativo, resultado de la asunción de ciertas exigencias ético-políticas y que sirve para evaluar los diferentes sistemas jurídico-positivos (cfr. F. LAPORTA, «Imperio de la ley. Reflexiones sobre un punto de partida de Elías Díaz», en Doxa. Cuadernos de Filosofía del Derecho, núms. 15-16, vol. I, 1994, 133 y ss.). Por ello, porque el concepto de «Estado de Derecho» tiene la referida naturaleza normativo-valorativa, se explica que en torno a él puedan desarrollarse las actitudes crítico-prácticas propias de un «aceptante». Con el concepto de «Estado constitucional de Derecho» ocurre exactamente lo mismo. 
sin embargo, lo que nos propone FERRAJOLI es que en cuanto juristas operemos como que es así. Nos propone que seamos leales al positivismo aunque para ello debamos vaciar el garantismo. La insuficiencia de sus planteamientos proviene de la necesidad de dotar de valor y de sentido a las referidas propiedades estructurales. Entre otras cosas, porque la rigidez y la normatividad de las constituciones sólo son valiosas (no en vano se trata de puras técnicas de protección) en la medida en que sean garantía de cosas a su vez consideradas valiosas. Estas mismas técnicas al servicio, por ejemplo, no de una expectativa considerada valiosa y, por tanto, merecedora de ser protegida en forma de un derecho, sino de un privilegio (es decir, de una expectativa no valiosa y/o no justificada) resultan simplemente insoportables e irracionales. Sólo si se introduce el componente de valor inserto en esas mismas constituciones tiene sentido, en mi opinión, hablar de «garantismo». Una garantía independizada del valor de lo garantizado es, me parece, un sinsentido en términos prácticos ${ }^{6}$; siguiendo la terminología de MERTON se trataría de mero ritualismo ${ }^{7}$.

En algún momento, da la impresión de que FERRAJOLI abandona su peculiar formalismo y cede ante la evidencia. Así escribe:

«De este modo, el antiguo y recurrente contraste entre razón y voluntad, entre ley de la razón y ley de la voluntad [...] ha sido en gran parte resuelto por las actuales constituciones rígidas, a través de la positivación de la "ley de la razón" —aun cuando históricamente determinada y contingente- bajo la forma de los principios y de los derechos fundamentales estipulados en ellas, como límites y vínculos a la "ley de la voluntad", que en democracia es la ley del número expresada por la voluntad de la mayoría» (p. 25).

Suscribo completamente este párrafo de FERRAJOLI. En realidad, creo que la referencia que hace a la historia sólo puede espantar a algún iusnaturalista ultramontano. Hoy en día, ¿quién sostiene seriamente que hay principios jurídicos fuera de la historia? Ahí no está la discusión. El problema de FERRAJOLI es que o bien abandona su positivismo o bien no puede hablar de ley de la razón. Su positivismo, porque es estrictamente incompatible con hablar de ley de la razón. Así escribe:

${ }^{6}$ Lo mismo podría decirse a propósito de la noción de derecho fundamental de FERRAJOLI. Los rasgos de fundamentalidad, universalidad e inalienabilidad son entendidos como una combinación de, por un lado, el resultado de actos de voluntad (todos los derechos son siempre situaciones constituidas, nunca constituyentes) y, por otro, características puramente formales. En particular, el rasgo de la inalienabilidad, que en la comprensión general de los derechos fundamentales aparece vinculada a su dimensión de valor objetivo y que apoya la interpretación de la constitución como ley de la razón, se convierte en la concepción de FERRAJOli en un puro derivado lógico de la universalidad, entendida también en sentido puramente lógico. Sobre ello, véase M. AlEMANY, «La inalienabilidad de los derechos humanos», en P. BRUNET y F. J. ARENA (dirs.), Cuestiones contemporáneas de teoría analítica del Derecho, Madrid, Marcial Pons, 2011, 17-52. Escribe ATIENZA a propósito de la cuestión del valor: «si se confronta la definición de FERRAJOLI de los derechos fundamentales con las que pueden encontrarse en algunos iusfilósofos analíticos (se refiera a Francisco LAPORTA) se llega fácilmente a la conclusión de que hay una nota que estos últimos incluyen, pero que falta en el concepto [...] de FERRAJOLI: se trata de la idea de valor, de que los derechos humanos [...] representan o incorporan algo así como las razones más fuertes, vale decir, razones o exigencias de carácter moral», en M. AtiEnZA, «Sobre Ferrajoli y la superación del positivismo jurídico», en L. FerRAJOLI, J. J. Moreso y M. Atienza, La teoría del Derecho en el paradigma constitucional, Madrid, Fundación Coloquio Jurídico Europeo, 2008, 158-159.

7 Como es sabido, Robert K. MERTON clasificaba en cinco formas diferentes la adaptación de los individuos a los grupos sociales. Dentro de ellas, el ritualismo se caracterizaba por el rechazo de los fines definidos culturamente (cultural goals) y la aceptación de los medios institucionales. Cfr. R. K. MERTON, «Social Structure and Anomie», en American Sociological Review, vol. 3, núm. 5 (oct. 1938), 676 y ss. 
«La finalidad de esta intervención [el artículo aquí criticado] es sostener, por el contrario, una concepción del constitucionalismo estrictamente "iuspositivista", entendiendo por "positivismo jurídico" una concepción y/o un modelo de Derecho que reconoce como "Derecho" a todo conjunto de normas puestas o producidas por quien está habilitado para producirlas, con independencia de cuáles fueren sus contenidos y, por tanto, de su eventual injusticia» (p. 16).

Y como no abandona el positivismo, tiene que abandonar su «ley de la razón», pues no es más que una pura «ley de la voluntad». El lex superior del constitucionalismo positivista de FERRAJOLI significa exclusivamente auctoritas superior (es decir, voluntad superior). Si bien se considera, no deja espacio alguno para que quepa hablar de un genuino constitucionalismo de los derechos como ley de la razón. Y ello nos lleva al siguiente momento que una buena teoría de la constitución debe ser capaz de distinguir y de integrar.

1.2. En Darse una constitución incluyo los aspectos relativos al tratamiento de la constitución como fuente-acto.

Escribe FERRAJOLI en Principia iuris:

«El decimocuarto postulado [...del positivismo jurídico...] excluye que puedan ser constituyentes figuras consistentes en expectativas o en no permisiones positivas o negativas. Se deducirá [...] que "constituyente" no puede ser ni un derecho, ni una obligación ni una prohibición, sólo un poder y, precisamente, aquella específica facultad que llamaremos "poder constituyente" [...] Todos los derechos en efecto, incluidos los fundamentales, consisten en expectativas $[\ldots]$ constituidas» ${ }^{8}$.

Tenemos pues que, según FERRAJOLI, el Estado constitucional se identifica en términos jurídicos sólo por la rigidez constitucional; y que aunque la constitución del Estado constitucional no es más que un mero producto de la voluntad («constituyente sólo puede ser un poder») sus normas se atrincheran (aseguran o garantizan) como si fueran la ley de la razón. Es evidente que en un sistema jurídico-político que cuenta con la «forma constitucional» (es decir, con una «constitución formal») se ha tomado una «decisión» respecto de qué cuenta como constitución dentro de ese sistema jurídico-político, pero de ahí no se sigue nada suficiente para la identificación del Estado constitucional. Sólo algunos Estados que cuentan con una constitución formal, rígida y regulativa son Estados constitucionales: aquellos cuyas constituciones satisfacen ciertos «contenidos». Lo característico (y distintivo) no está sólo en la forma ni sólo en la sustancia. Sino en que la forma (la lex superior) opera como garantía de cierta sustancia, no de cualquier sustancia. Si uno acepta este elemental razonamiento se ve abocado a extraer el siguiente corolario. En toda constitución de un Estado constitucional hay normas y principios necesarios. No es concebible un Estado constitucional sin derecho a la libertad de expresión, sin derecho de asociación o sin los principios de independencia e imparcialidad de los jueces, etc. Sin esos derechos y/o principios podría haber lex superior pero no Estado constitucional de Derecho. Es discutible cuál es el contenido «esencial» del Estado constitucional (aquél sin el cual no podría hablarse de Estado constitucional), pero lo que, en mi opinión, resulta indudable es que la «ley de la razón» no se identifica sólo por la forma jurídica que adopta. Sino que es al revés: se le da cierta forma porque se la considera «ley de la razón». Entender el Estado cons-

\footnotetext{
8 L. FerRajoli, Principia iuris. 1. Teoría del diritto, Laterza, 2007, 100-101 (la traducción es mía).
} 
titucional desde la perspectiva de las fuentes-acto supone darse cuenta de que hay un núcleo en el que opera el tan denostado por FERRAJOLI «veritas, non auctoritas facit legem». Tomemos como ilustración de lo que se quiere decir el art. 16 de la Constitución española. Es trivialmente cierto que la forma constitucional iguala los apartados 1 (reconocimiento de la libertad ideológica, religiosa y de culto) y 3 (deber de cooperación de los poderes públicos con la Iglesia Católica) de dicho artículo. No hay duda, ambos apartados son igualmente fragmentos de la Constitución española. Pero de ahí no se sigue que «pesen» lo mismo en términos jurídicos. El apartado 1 expresa un principio necesario del constitucionalismo democrático (de forma tal que si ese contenido fuera eliminado del texto y/o de la práctica constitucional difícilmente diríamos que estamos ante un Estado constitucional de Derecho), mientras que el apartado 3 expresa todo lo más (en el mejor de los casos) un contenido idiosincrásico (podría no formar parte de la Constitución española o ser derogado sin que ello afectase a la calificación del orden jurídico-político español como Estado constitucional). Detrás de esta afirmación hay argumentos «no formales», «para-formales» o «meta-formales», pero en ningún caso, meta-constitucionales o meta-jurídicos. Es el producto de entrar a «ponderar» sustancia jurídica y de tomar en consideración, dentro de las normas constitucionales, la distinción entre normas necesarias y normas contingentes (es decir, idiosincrásicas):

1.2.1. En toda constitución de un Estado constitucional hay normas y principios necesarios y que, en consecuencia, son inderogables. No sólo en el sentido de que la rigidez constitucional hace difícil (o altamente improbable) la derogación de su formulación normativa; sino en el sentido de que si se derogan, entonces el Estado en cuestión dejaría de ser un Estado constitucional. Por ejemplo, no es concebible la derogación del principio de libertad de expresión, o del de independencia de los jueces, o del derecho de asociación; pueden cambiar las respectivas formulaciones normativas en que se «reconocen» esos principios y/o derechos, pero no es posible su eliminación como principios y derechos y seguir hablando de Estado constitucional de Derecho. Son, en este sentido, principios necesarios del Estado constitucional de Derecho. Se puede discutir cuál es ese núcleo esencial de contenidos del Estado constitucional, pero lo que es incuestionable, en mi opinión, es que esa «ley de la razón» de la que hablaba FERRAJOLI no se identifica por su forma jurídica; sino que se le da esa forma por sus méritos. En este sentido, entender el constitucionalismo jurídico supone darse cuenta de que hay un ámbito en el que opera el «veritas, non auctoritas, facit legem». Esto, en mi opinión, es una obviedad. Tan es así que, por ejemplo, para explicar por qué esos principios forman parte de la Constitución española nadie necesita acudir a la noción de poder constituyente. Si esos principios y/o derechos no estuvieran en la Constitución española, el constituyente español no habría constituido un Estado constitucional. En relación con estos contenidos (es decir, con la ley de la razón) explica bastante más la noción de «pretensión de corrección» que la noción de «poder constituyente»?.

9 La Constitución española suministra un espléndido ejemplo de lo que significa «principios necesarios» del constitucionalismo. En efecto, su título VI, «Del poder judicial», no hace ninguna alusión a la imparcialidad de los jueces, al principio de imparcialidad; es decir, no lo incluye dentro del conjunto de principios relevantes que deben guiar la función judicial. La pregunta importante que hay que responder es si conforme al Estado constitucional español el principio de imparcialidad judicial está a disposición o no del legislador. Es decir, si el legislador mediante ley puede ponerlo o quitarlo según le parezca. En mi opinión, el principio de imparcialidad judicial es un principio constitucional aunque la constitución promulgada no lo reconozca y, en consecuencia, 
1.2.2. En toda constitución «positiva» de un Estado constitucional hay también normas que expresan contenidos «idiosincrásicos»; es decir, contenidos cuya explicación va referida a las peculiaridades históricas y sociales de cada Estado constitucional. En este sentido, en cada constitución hay normas cuya explicación necesita de la noción de poder constituyente; entendido éste como expresión de la singularidad histórica de cada Estado constitucional. Por ejemplo, la noción de poder constituyente es superflua para explicar por qué la Constitución española reconoce la libertad de expresión, pero es esencial para explicar por qué España es una monarquía y no una república. Es superflua para explicar el reconocimiento de la libertad religiosa pero es básica para explicar el deber de cooperación con la Iglesia Católica. Es decir, hay todo un ámbito en las constituciones positivas en el que es cierto el dictum de «auctoritas, non veritas, fácit legem».

En definitiva, la constitución del Estado constitucional es, sin duda, una fuente promulgada (una fuente-acto) y, en este sentido, es siempre susceptible de ser presentada como el producto de una voluntad constituyente, pero de ahí no se sigue que para el «constitucionalismo jurídico» el Estado constitucional se reduzca jurídicamente a la noción de lex superior. Si se huye del formalismo jurídico y del segregacionismo discursivo de FERRAJOLI algunas cosas se explican mucho mejor (como, por ejemplo, el desarrollo de un constitucionalismo común) y algunos temores y/o peligros simplemente se conjuran. En particular, el riesgo de «constitucionalismo ético» que tanto preocupa a FERRAJOLI es el producto de hacer una lectura meramente formalista de las constituciones positivas, pues supone inferir la moralidad de la sustancia a partir de la forma constitucional. Quien no incurra en ese formalismo y, por ejemplo, use la distinción recién considerada no tendrá dificultades para darse cuenta de que, en efecto, es posible que en una constitución positiva de un Estado constitucional haya normas constitucionales estrictamente «espurias». Normas que expresan un contenido idiosincrásico (son el producto de una voluntad) y que se juzgan como incoherentes con (es decir, que se consideran prohibidos por) los principios necesarios de un Estado constitucional. Naturalmente la calificación de «contenidos espurios» es el resultado de dar cierta prioridad a los principios necesarios frente a los contenidos idiosincrásicos; pero ahora eso no es lo importante. Lo fundamental es darse cuenta de que el constitucionalismo jurídico tiene que lidiar con una dialéctica (una tensión) entre los aspectos sustantivos y los aspectos autoritativos de la constitución. Para explicar (y gestionar) esa tensión hay, sin embargo, que abandonar el momento «darse una constitución».

1.3. En Vivir en constitución incluyo aquellos aspectos de la dinámica constitucional que se resisten a ser reducidos a la noción de sistema y que remiten más bien a la idea de «práctica» constitucional. Si bien se considera todo lo dicho en los dos epígrafes anteriores puede resumirse en lo siguiente: a) El Estado constitucional de Derecho no se identifica sólo por rasgos estructurales (como, por ejemplo, la lex superior de FERRAJOLI), hay también un componente valorativo o ideal, y b) en el Estado consti-

no es disponible por el legislador. Podría sostenerse que en realidad no se trata de un principio necesario sino un principio implícito, pues puede extraerse por interpretación del resto de normas constitucionales. Sin duda ello es así, pero mi tesis pretende ser más fuerte y es ésta: no puede haber (no es concebible el) Estado constitucional de Derecho sin principio de imparcialidad judicial. Y si las cosas son así, entonces el principio de imparcialidad judicial es un principio necesario del Estado constitucional de Derecho. 
tucional hay una cierta tensión entre el componente autoritativo de la constitución y el componente sustantivo. Es decir, en el Estado constitucional hay normas que son constitución porque lo quiso la autoridad y normas que son constitución con independencia de la voluntad del constituyente (si no hubieran sido promulgadas como parte de la constitución formal sólo cabrían dos alternativas: o bien se consideraría que están implícitas en la constitución o bien se consideraría que la constitución en cuestión no es la constitución de un Estado constitucional). Si se aceptan estos dos presupuestos es fácil de entender por qué para el constitucionalismo jurídico el fenómeno constitucional no es correctamente aprehensible a partir de la noción de sistema. En efecto, a pesar de que la constitución formal es una fuente-acto y de que opera como lex superior, la noción de sistema queda ampliamente desbordada por las siguientes razones. En primer lugar, porque el «constitucionalismo jurídico» bien entendido es consciente de que la referida tensión entre autoridad y sustancia no es estructuralmente eliminable y comprende que la cuestión constitucional no es reducible a un conjunto ordenado de enunciados jurídicos, es decir, no es reducible a la noción de sistema. Además, en segundo lugar, para el «constitucionalismo» — casi como su propio nombre indicano es sorprendente ni peligroso el desarrollo de las actitudes crítico-prácticas propias del aceptante del Estado constitucional; por ello, el constitucionalismo jurídico apunta hacia la generación de las actitudes adecuadas vinculadas a necesidades discursivas de justificación; es decir, apunta más hacia las exigencias deliberativas y argumentativas propias de la idea de práctica constitucional, que hacia las soluciones estructurales y sistemáticas ${ }^{10}$. En mi opinión, la insistencia de FERRAJOLI en adoptar exclusivamente el punto de vista externo acaba frustrando en términos prácticos sus propias empresas: un constitucionalismo puramente externo es «un constitucionalismo no constitucionalista»; igual que un garantismo puramente externo es vacío, es decir, «un garantismo no garantista».

\section{A PROPÓSITO DE LA TESIS DE LA NORMATIVIDAD}

La tesis ferrajoliana de la normatividad puede resumirse en lo siguiente. No hay diferencia estructural entre principios y reglas y, como consecuencia de ello, la insistencia en la distinción sólo produce el debilitamiento de la obligatoriedad de la constitución. Repitamos el esquema anterior.

\subsection{Tener una constitución}

\section{Escribe FERRAJOLI:}

«[...] no existe una real diferencia de estatuto entre la mayor parte de los principios y las reglas: siempre la violación de un principio hace de esto una regla que enuncia las prohibiciones o las obligaciones correspondientes» (p. 40).

10 Lo que desde el punto de vista externo se ve como contradicciones que piden una respuesta estructural y definitiva que haga posible la ordenación del sistema; desde el punto de vista interno se ve como tensiones dialécticas que no son eliminables en abstracto, que exigen el desarrollo de las actitudes adecuadas y que apuntan a marcos deliberativos y argumentativos. 
Es evidente que siempre que se viola el «principio de igualdad» se viola también la «prohibición de discriminación». Pero así formulados estamos siempre en el nivel de los principios: nos dicen lo que «debe ser» («tratar igual», es decir, «no discriminar») pero no definen un caso genérico (no dicen cuándo son aplicables esas soluciones normativas, ese «deber ser») ${ }^{11}$. Por ello, su aplicación exige desarrollar una cierta deliberación práctica. Frente a los principios, las reglas son normas que sí definen de manera cerrada un caso genérico; y precisamente por ello pueden ser aplicadas sin necesidad de hacer valoraciones. Pero la discrepancia con FERRAJOLI no está, en realidad, en este punto, sino en lo siguiente. FERRAJOLI no admite la distinción entre principios y reglas porque sólo toma en consideración el aspecto directivo de las normas, nunca su aspecto valorativo y/o justificativo. Aceptar la distinción de manera relevante supone asumir que entre las normas se dan no sólo relaciones de compatibilidad o de incompatibilidad en términos de cumplimiento, sino también relaciones de coherencia o de incoherencia valorativa en términos justificativos. Aceptar la distinción entre principios y reglas supone aceptar que los principios cumplen esa función justificativa en relación con las reglas. Los principios permiten ver a las reglas no sólo como meras manifestaciones de voluntad de una autoridad, sino como expresión de una ponderación de principios y, por tanto, dotadas de un sentido protector y promocional de ciertos bienes. Como es fácilmente comprensible, en la medida en que se toma en consideración la distinción entre el aspecto directivo y el aspecto justificativo de las normas empiezan a aparecer los fenómenos de la infrainclusión y de la suprainclusión a la hora de proceder a su aplicación. Y una vez que esto ocurre surgen inmediatamente dos preguntas: la primera es si un principio es reducible a las reglas que lo desarrollan y/o concretan. FERRAJOLI sostiene que sí, que sí es reducible; en mi opinión, la respuesta correcta es no ${ }^{12}$.

${ }_{11}$ Siempre he pensado que una buena manera de caracterizar los principios frente a las reglas es acudir a la noción de norma categórica de VON WRIGHT (G. H. VON WRIGHT, Norma y acción, Madrid, Tecnos, 1970, 91 y ss.). En efecto, a partir de la noción de condición de aplicación de una norma («aquella condición que tiene que darse para que exista la oportunidad de hacer aquello que es el contenido de una norma»), vON WRIGHT distingue entre normas categóricas (aquellas cuya condición de aplicación viene dada por el contenido) e hipotéticas (aquellas cuya condición de aplicación no puede ser derivada solamente de su contenido; por ello, al tener que mencionar la condición adicional adoptan la estructura condicional típica en la forma «si... entonces...»). Sobre ello, J. Aguiló Regla, Teoría general de las fuentes del Derecho (y el orden jurídico), Barcelona, Ariel, 2000, 135 y ss.

12 Una buena manera de ilustrar esta cuestión de si un principio se reduce o no a las reglas que lo concretan y/o desarrollan es recurrir a la doctrina jurisprudencial sobre las causas de abstención y de recusación de jueces y magistrados que sostiene que se trata de causas tasadas; es decir, que se trata de una lista de causas que no es ampliable ni restringible en ningún caso. No es éste el lugar apropiado para detenerse en extenso en ello, pero me parece que lo que hace esa línea jurisprudencial no es más que confundir el principio jurídico de la imparcialidad con las reglas jurídicas de la imparcialidad. En realidad, el principio de imparcialidad es la razón (justificativa) por la que se han establecido las reglas, es decir, las causas de abstención y de recusación; y precisamente por ello, el principio no puede quedar reducido a esas reglas. Como ya se ha dicho, las reglas en general tienen una formulación que hace que en ocasiones su aplicación pueda generar casos anómalos de infrainclusión o de suprainclusión a la luz de las razones justificativas subyacentes a las mismas (los principios). Y si esto es así, no tiene sentido negar toda posibilidad a que se produzca un caso en el que a la luz del principio de imparcialidad parezca plenamente justificada la abstención o la recusación, aunque dicho caso no sea estrictamente subsumible en ninguna de las reglas establecidas; es decir, no tiene sentido negar toda posibilidad de infrainclusión de las reglas (es lo que ocurría, en mi opinión, en la instrucción del caso GAL por parte del juez Baltasar Garzón: no encajaba estrictamente en ninguna de las reglas y, sin embargo, estaba justificada la recusación), como tampoco tiene sentido negar toda posibilidad de sobreinclusión de esas mismas reglas (es lo que ocurría, en mi opinión, en la recusación del magistrado del Tribunal Constitucional Pablo Pérez Tremps a propósito del caso del Estatut d'Autonomía de Catalunya: encajaba en las reglas y, sin embargo, nunca debió 
La segunda pregunta es qué significa ser leal al Derecho, a las normas. En mi opinión, ser leal a las normas no es serlo sólo a su expresión directiva, sino también a las razones subyacentes. FERRAJOLI parece ver en ello un «vaciamiento de las fuentes» y una defensa del activismo judicial, cuando en realidad lo único que hay es una conciencia clara de que la conducta ritualista es una forma de conducta desviada.

\subsection{Darse una constitución}

\section{Escribe FERRAJOLI:}

«En todos los casos, sería oportuno que la cultura iusconstitucionalista, en lugar de asumir como inevitables la indeterminación del lenguaje constitucional y los conflictos entre derechos [...] promoviese el desarrollo de un lenguaje legislativo y constitucional lo más preciso y riguroso posible» (p. 51).

En mi opinión, FERRAJOLI se equivoca al trasladar directamente lo que pueden ser virtudes del lenguaje de las leyes y de los reglamentos al lenguaje de las constituciones. Parece no percatarse de que mientras que para la legislación y los reglamentos funciona el principio de lex posterior, para las constituciones rígidas este principio está prácticamente vedado (la función de la rigidez es precisamente «bloquear» el lex posterior). Naturalmente nada impide que en una constitución haya normas cerradas, cuya aplicación excluya completamente cualquier forma de deliberación; es decir, que haya reglas en sentido estricto. Incluso podemos celebrar que haya normas de este tipo. Tenemos ejemplos bien claros de normas bien precisas y perfectamente justificadas, como la prohibición de la pena de muerte o de la tortura. Pero la precisión del lenguaje de las constituciones se enfrenta con dos problemas que, si bien son abordables, nunca son completamente eliminables: a) El problema del consenso (en muchas ocasiones sólo somos capaces de alcanzar acuerdos no muy precisos). Y b) el problema del compromiso (tenemos inseguridad respecto del alcance que en abstracto estamos dispuestos a dar a ciertos contenidos normativos que van a pasar a ser prácticamente inderogables). No es sorprendente que un absolutista moral no dé mucha importancia a ninguno de estos problemas: el consenso es innecesario (la intersubjetividad le importa realmente poco) y la inseguridad sobre el contenido futuro de lo correcto no es algo que le caracterice. Por ello no resulta extraño que un absolutista moral sea partidario de una constitución rígida (inmodificable) y simultáneamente cerrada a la deliberación en su aplicación. Lo que sí resulta bien llamativo y extraño es que un no-cognoscitivista sea partidario de una constitución sustantiva, rígida y cerrada a la deliberación; es decir, partidario de un «deber ser» no derogable y no moldeable en su aplicación. Este planteamiento de FERRAJOLI es, en mi opinión, un sinsentido en términos prácticos ${ }^{13}$.

de ser admitida la recusación). En definitiva, aceptar la distinción entre principios y reglas supone aceptar la dialéctica principios/reglas, no la reducción de los principios a las reglas que los desarrollan y/o concretan.

13 En «Sobre el constitucionalismo y la resistencia constitucional» (en Doxa. Cuadernos de filosofía del Derecho, núm. 26, 2003, 289-319), trabajo escrito en memoria de Francisco TOMÁs y VALIENTE y destinado a analizar su noción de «resistencia constitucional», sostuve que quien fuera consciente de, por un lado, los problemas del consenso y del compromiso (la inseguridad práctica), y, por otro, del problema de la tiranía de las generaciones pasadas, se vería limitado por una función que relacionara la rigidez y la apertura constitucionales. Esta función vendría a determinar que si hay problemas de consenso y/o de inseguridad práctica, a medida que se incrementa la rigidez constitucional tiene que incrementarse su apertura regulativa. 
Repito, el error consiste en aproximar demasiado constitución y legislación; y en trasladar sin más lo que son (o pueden ser) virtudes de la legislación a virtudes de los textos constitucionales. FERRAJOLI parece olvidar que mientras que la legislación es dinámica (opera con el lex posterior) la constitución rígida es estática (la rigidez consiste precisamente en hacer altamente improbable, si no imposible el lex posterior). Precisamente por ello el tratamiento que hay que dar a los problemas de consenso y de compromiso (inseguridad práctica) en una y otra fuente-acto son completamente distintos. Tan irracional en términos prácticos es trasladar las virtudes de la legislación a la constitución, como trasladar las virtudes de la constitución a la legislación. La dialéctica constitución-ley no es ni por asomo una extensión de la tradicional jerarquía normativa entre ley y reglamento.

\subsection{Vivir en constitución}

La forma constitucional rígida plantea el problema que representa el paso del tiempo. Si la legislación es el instrumento ordinario para el cambio en un sistema jurídicopolítico, la rigidez de una constitución regulativa parece enredar al constitucionalismo en un dilema. Por un lado, si una constitución es rígida, entonces se rompe la igualdad democrática y se somete a los vivos a la voluntad de los muertos. Pero, por otro lado, si una constitución no es rígida, es decir, si los derechos no están sustraídos al juego de las mayorías, entonces — suele decirse- los derechos no están garantizados, es decir, «no hay constitución». De nuevo, y sin extenderme mucho, en mi opinión, esta tensión entre quienes «se dieron una constitución» (los muertos) y quienes «tienen una constitución» (los vivos) tampoco es susceptible de recibir una respuesta estructural o definitiva. La síntesis armónica entre unos (los muertos) y otros (los vivos) sólo

Si tomamos esta función es fácil mostrar que hay cuatro modelos teóricos incompatibles con el consitucionalismo resistente (modesto, sensato) que profesaba TOMÁs y VALIENTE. En efecto, si se toma, por un lado, la flexibilidad absoluta como punto mínimo de la rigidez (0) y la inmodificabilidad como punto máximo (10) y, por otro, el cierre absoluto (es decir, normas que sólo cabe aplicar, no determinar) como punto mínimo de la apertura (0) y la ausencia de guía regulativa de la conducta como punto máximo apertura (10), es fácil mostrar cuatro modelos incompatibles con un constitucionalismo sensato en términos prácticos. Son los siguientes:

a) El primer modelo vendría dado por aquellos que se sitúan en el punto $(0,0)$, es decir, partidarios de una normativa completamente flexible (modificable) y cerrada (sólo ejecutable); vendrían a representar el anticonstitucionalismo legalista, pues negarían legitimidad a la forma constitucional en favor de la legislación: el punto 0 de rigidez implica que no hay diferencia formal entre legislación y constitución y el punto 0 de apertura implica todas las ventajas derivadas del imperio de la ley (gobierno per leges en el sentido de reglas).

b) El segundo modelo vendría dado por aquellos que se sitúan en el punto $(0,10)$, es decir, partidarios de una normativa completamente flexible (modificable) y completamente abierta y que los podríamos llamar judicialistas radicales (o también particularistas extremos); negarían la forma constitucional y afirmarían una legislación de valores o principios de manera que las reglas jurídicas sólo fueran un producto del Derecho del caso, del Derecho de los jueces (vendrían a ser los partidarios del gobierno de los hombres).

c) El tercer modelo sería el de aquellos que se sitúan en el punto $(10,0)$, es decir, partidarios de la inmodificabilidad de una constitución cerrada y que vendrían a representar lo que podría llamarse el fundamentalismo constitucional sustantivista, pues estarían defendiendo que se formulasen normas bien precisas (cerradas a la deliberación) y prácticamente inmodificables. En este grupo parecen encontrarse los absolutistas morales y FERRAJOLI.

d) El cuarto y último modelo sería el de aquellos que se sitúan en el punto $(10,10)$, es decir, los partidarios de la inmodificabilidad absoluta de una constitución puramente procedimental y completamente abierta ( mocrático o constitucionalismo procedimentalista. 
puede expresarse mediante nociones inestables y dialécticas como la de «continuidad de una práctica» que dan cuenta del aspecto ideal y permiten eliminar los términos indeseables de puro sometimiento al pasado, por un lado, y de ausencia de garantía de los derechos (de estabilización de las expectativas relativas a los derechos), por otro. Nuevamente, al igual que en el caso anterior, la noción de sistema como conjunto ordenado de enunciados jurídicos queda completamente desbordada para dar cuenta de la dinámica constitucional; la idea de práctica apunta hacia exigencias deliberativas $\mathrm{y}$ argumentativas y hacia el desarrollo de las actitudes adecuadas.

\section{A PROPÓSITO DE LA TESIS DE LA CORRELATIVIDAD}

La tesis de la correlatividad sostiene que los enunciados de derechos significan exactamente lo mismo que los enunciados que expresan sus deberes correlativos.

\subsection{Tener una constitución}

\section{Escribe FERRAJOLI:}

«Pero más allá del estilo, cualquier principio que enuncia un derecho fundamental - por la recíproca implicación que liga a las expectativas en que consisten los derechos, con las obligaciones o prohibiciones correspondientes - equivale a la regla consistente en la correlativa obligación o prohibición [...] El Decálogo, por otro lado, está expresado en reglas ("no matar", "no robar" y similares) que tienen exactamente el mismo significado que los derechos correspondientes (el derecho a la vida, el derecho de propiedad y similares)» (p. 39).

Si bien se considera, esta tesis de FERRAJOLI es un corolario de la tesis criticada en 2.1. Allí negaba las relaciones de justificación entre normas y, por tanto, la relevancia de la distinción entre principios y reglas. Aquí, de nuevo, toma en consideración únicamente el aspecto directivo del lenguaje normativo y, por tanto, piensa que los enunciados de derechos son reducibles sin pérdida de significación a enunciados que expresan los deberes correlativos.

En sentido puramente directivo es cierto que los enunciados jurídicos de derechos son traducibles a enunciados de deberes. Pero en términos justificativos la correlatividad entre derechos y deberes se pierde; y, por tanto, la traducción de los enunciados de derechos a enunciados de deberes sí supone pérdida de significación. El «reconocimiento» de derechos justifica la «imposición» de deberes, mientras que la imposición de deberes no sirve para justificar la titularidad de los derechos. El derecho es, además del correlativo del deber en términos directivos, el título que justifica recurrir al deber como técnica de protección ${ }^{14}$. Si se considera sólo el aspecto directivo y se mira exclusivamente por el lado del deber entonces no hay manera de distinguir entre «tener un derecho» y «gozar de un privilegio». A FERRAJOLI, sin embargo, no parece importarle demasiado: toma en consideración sólo el aspecto directivo de las normas y prescinde por completo del aspecto justificativo del par «derecho-deber».

${ }_{14}$ Cfr. F. LAPORTA, «Sobre el concepto de derechos humanos», en Doxa. Cuadernos de filosofía del Derecho, núm. 4, 1987, 23-46. 


\subsection{Darse una constitución}

Los derechos en general se formulan precisamente en forma de principios porque, a pesar de que respecto de cada uno de ellos hay casos paradigmáticos en relación con los que no hay problemas de consenso ni de inseguridad, no somos capaces de determinar exhaustivamente y de una vez por todas los deberes que se corresponden con la satisfacción y la garantía de los derechos. Hablar de progreso en materia de derechos, en realidad, no consiste tanto en formular nuevos derechos cuanto en nuevas especificaciones y nuevas imposiciones de deberes como garantía. Aceptar esta prioridad justificativa de los derechos respecto de los deberes significa que un derecho nunca puede quedar reducido a un conjunto cerrado de deberes correlativos (salvo en un sentido meramente trivial de lo que significa «tener un derecho»). En mi opinión, hay mucho ritualismo en la confusión entre derechos y deberes; es decir, entre los derechos y las técnicas de protección de los derechos.

\subsection{Vivir en constitución}

Siempre he pensado que si tiene sentido alcanzar acuerdos constitucionales que consisten en principios, en normas abiertas (lo que en ocasiones se ha llamado acuerdos incompletamente teorizados) ${ }^{15}$ prácticamente inderogables en el momento de «darse una constitución», tiene que tener sentido interpretar y aplicar esas mismas normas durante la vigencia de la constitución, en el momento de «tener una constitución». En mi opinión, el sentido regulativo de los principios constitucionales sólo se ve claro si se asume que el sentido de darse una constitución es el de fundar una práctica constitucional orientada por principios, derechos y valores. No se trata por tanto de que la norma constitucional resuelva ex ante los problemas y/o conflictos que puedan surgir (esas son las ventajas de la legislación), sino más bien de que la constitución oriente la solución de todos esos problemas. En algunos casos, las normas constitucionales cerradas exigirán consistencia respecto de todas las normas del orden jurídico, como por ejemplo ocurre con la prohibición de la pena de muerte o de la tortura. Pero en otros casos, las normas constitucionales abiertas exigirán desarrollo tanto legislativo como jurisprudencial. Muchas de las perplejidades que genera la interpretación de las normas constitucionales se disuelven en gran medida si uno se aproxima a la constitución formal como un documento fundacional de una práctica orientada por principios y derechos, en lugar de aproximarse a ella como un documento normativo acabado en el que se hallan ya cerradas las respuestas a problemas jurídico-políticos que puedan surgir. Este planteamiento responde a la idea antes referida de «continuidad de una práctica constitucional», en la que lo esencial es eludir los términos indeseables de «puro sometimiento al pasado» (constitución rígida y cerrada) y de «ausencia de garantías de los derechos» (constitución flexible o constitución rígida pero puramente procedimental).

15 Cfr. C. R. Sunstein, «Constitutional Agreements Whithout Constitutional Theories», en Ratio iuris, vol. 13, núm. 1, mayo 2000, 117-130. 


\section{A MODO DE CONCLUSIÓN}

La ordenación en tres momentos y/o contextos («tener una constitución», «darse una constitución»y «vivir en constitución») está construida sobre lo siguiente. Según la terminología tradicional propia de las fuentes-acto, mientras que «tener una constitución» se corresponde con la «estática constitucional»; «darse una constitución» se corresponde con la «dinámica constitucional». Ahora bien, resulta realmente difícil hablar de «dinámica constitucional» cuando el sentido de promulgar una constitución rígida es precisamente inhibir el principio de lex posterior; es decir, hacer imposible o altamente improbable el cambio deliberado del texto constitucional. La expresión «dinámica constitucional» genera, en este sentido, una imagen «engañosa» de la constitución como «fuente-acto», pues la aproxima demasiado a la legislación ${ }^{16}$. Exagerando un tanto las cosas, uno se siente tentado a decir que respecto de una constitución rígida sólo hay estática constitucional. Esa es la razón por la que opté por la expresión «darse una constitución», porque reflejaba bien el aspecto fundacional de la promulgación de una constitución rígida y permitía evitar el «engaño» que supone hablar de dinámica constitucional cuando, en realidad, se está ante una cuasi-estática constitucional.

El tercer momento, «vivir en constitución», es el resultado de asumir que la noción de sistema jurídico ha quedado completamente desbordada para dar cuenta de nuestras realidades constitucionales. Y ello es así precisamente por la combinación de estática-estática que acabamos de referir: estática es la constitución como norma y estática es la constitución como acto (sólo hay acto de promulgación). Esto no puede sorprender demasiado. Si bien se considera, se trata del problema clásico que la filosofía política ha formulado como un conflicto entre generaciones (entre los muertos y los vivos), sólo que aquí está formulado en términos jurídicos. En ambos casos el desafío que ello plantea es el mismo: hasta qué punto puede considerarse racional una acción jurídica y/o política cuyo sentido se halla meramente en la sumisión al pasado ${ }^{17}$. Pues bien, la idea de práctica constitucional es fundamental para dar salida a este desafío. No me voy a detener en ello, pero la clave para aceptar la idea de práctica constitucional radica en darse cuenta de que la secuencia de la dinámica jurídica convencional, que es «acto-norma-acto», no es aplicable a la «dinámica» de las constituciones rígidas. De esta inaplicabilidad surge la necesidad teórica de sustituir esa secuencia por la de «acto-norma-práctica»; es decir, la necesidad de dar cuenta del momento «vivir en constitución». De ello ha sido plenamente consciente el constitucionalismo jurídico y

16 En mi opinión, el trabajo de FerRAJOLI adolece de este inconveniente. Las siguientes palabras de FERRAJOLI, tal vez, sirvan de ilustración: «Por otro lado, debemos darnos cuenta de que la oscuridad, la vaguedad y la indeterminación del lenguaje legal, aun cuando en alguna medida ineliminables, no son simples defectos de la legislación. Son un vicio jurídico de ésta, porque violan los principios de la separación de los poderes y de la sujeción de los jueces a la ley, y, por ello, comprometen el mantenimiento del edificio del Estado de Derecho en su totalidad. Por eso, la ciencia jurídica debería hoy retomar el programa ilustrado de Gaetano FILANGIERI y de Jeremy BENTHAM de una "ciencia de la legislación", integrándolo con el programa de una "ciencia de la constitución”, como la llamó Giandomenico Romagnosi. Pasada la época de las primeras constituciones, que se caracterizaban inevitablemente por un lenguaje declamatorio, nada impide el desarrollo de una técnica de formulación de las normas legislativas y constitucionales — de las reglas y de los principios, como así también de sus límites y de los límites a sus límites, a su vez enunciados explícitamente- en un lenguaje lo más simple, claro y preciso posible» (pp. 51 y 52).

17 Cfr. M. Weber, Economía y sociedad, México, Fondo de Cultura Económica, 10. ${ }^{a}$ reim., 1993, 20. 
a esta tarea de construcción jurídica se ha entregado a fondo. La noción de principio está en el centro de esta tarea: una norma inderogable (prácticamente inderogable) y abierta a la deliberación.

Dentro del constitucionalismo caben otras vías distintas de la anterior para intentar resolver el problema que representa el «estática-estática» recién referido. Aquí voy a mencionar dos de esas vías, aunque, adelanto ya, me parecen ambas desviaciones respecto del «constitucionalismo pleno»; construyen en algún sentido «un constitucionalismo no constitucionalista». Y son desviaciones porque detrás de ellas se esconden, respectivamente, el relativismo moral y el absolutismo moral. La primera de estas dos formas de constitucionalismo «desviado» consiste en hacer meramente procedimentalista al constitucionalismo; es decir, en considerar que la constitución rígida sólo establece (o interpretar que sólo establece) exigencias de tipo procedimental. Se rompe el esquema «estática-estática» por la vía de hacer completamente abierta la regulación constitucional en términos sustantivos. Si bien se considera, esta salida consiste en reducir el constitucionalismo rígido a la constitucionalización del modelo del «gobierno de las leyes». Esta forma de entender el constitucionalismo casa especialmente bien con el relativismo moral y el no cognoscitivismo; y suele ir acompañado de la consideración de que la tolerancia es la virtud cívica más importante y de que la democracia es el régimen político adecuado. La otra forma de constitucionalismo desviado consiste en hacer «fundamentalista» al constitucionalismo. El «estática-estática» propio del constitucionalismo rígido y regulativo no es un problema para este constitucionalismo siempre y cuando lo que se constitucionalice sea la «ley de la razón». Obviamente se trata de una «ley de la razón» que está más allá de los problemas de consenso y de compromiso antes referidos y que, en consecuencia, se expresa (o es deseable que se exprese) en forma de reglas. Esta manera de entender el constitucionalismo rígido casa especialmente bien con el «absolutismo moral».

En mi opinión, el relativismo y el absolutismo son desviaciones en relación con el constitucionalismo pleno o genuino. La desviación relativista del constitucionalismo tiende hacia el procedimentalismo (la rigidez protege sólo procedimientos, no contenidos); la desviación absolutista del constitucionalismo tiende a hacerse cerrado a la deliberación (sigue el modelo de regulación de las reglas). Por el contrario, el constitucionalismo pleno (no desviado) se hace rígido (sin lex posterior) y abierto a la deliberación (sigue el modelo de regulación de los principios). Dentro de este marco queda claro, me parece, el drama que representa el constitucionalismo que FERRAJOLI nos propone, pues se queda con «lo peor de cada casa»: es relativista (él dirá que no cognoscitivista) respecto de cuáles son los derechos y los principios justificados (respecto de qué proteger) y es absolutista respecto de la técnica de protección elegida (reglas cerradas a la deliberación e inmodificables). 